\title{
Bravos novos mundos: uma leitura pós-colonialista sobre masculinidades ocidentais
}

\begin{abstract}
Resumo: O objetivo deste ensaio é discutir, com base numa perspectiva pós-colonialista, o papel das masculinidades ocidentais em dois momentos de expansão da ordem internacional: as expansões colonial e imperialista dos séculos XVI a XIX e a construção de uma ordem internacional globalizada nos séculos XX e XXI. Ainda que os conceitos que definem tais masculinidades variem com base nas diferenças de cultura, tempo e locais identitários, elas estabeleceram hierarquias entre identidade e diferença. Mesmo assim, é possível pensar no reconhecimento da diversidade e na exploração das possibilidades alternativas das "zonas de contato" psicológico e social. Isso ocorreria a partir do compartilhamento de experiências e de críticas às formas de produção da alteridade consolidadas por relações binárias de poder nas instituições político-sociais, visando à superação de tais perspectivas excludentes no pensamento e na prática. Viabiliza-se, assim, a conversação entre tradições que respondem à opressão gerada no processo de reprodução das masculinidades ocidentais.
\end{abstract}

Palavras-chave: Relações Internacionais; masculinidades; pós-colonialismo.

Copyright (c) 2010 by Revista Estudos Feministas.

1 Segundo Yosef LAPID, 1989, tal momento é marcado pelo fim do consenso epistemológico positivista e pelo questionamento de critérios para a avaliação de construção teórica, como validade empírica, previsão e explicação. Dentre os novos temas que emergem nesse contexto, cabe destacar que a nova filosofia da ciência insiste que somente construções de larga escala e multicamadas como paradigmas e programas de pesquisa devam ser qualificados como unidades básicas de produção, acúmulo e conservação do conhecimento,
No contexto do desenvolvimento das perspectivas pós-positivistas na teoria de Relações Internacionais, ${ }^{1}$ as abordagens pós-colonialistas vieram ganhando cada vez mais espaço ao longo desta década. Tais abordagens evidenciam a inabilidade das Relações Internacionais na formulação de respostas criativas à diferença - ainda traduzida pelas abordagens teóricas tradicionais da área como uma "ameaça" ou uma "anomalia" - e propõem a reimaginação crítica das origens e do perfil da área como relações interculturais a partir de uma perspectiva etnológica. A diferença é concebida como um recurso de autoavaliação capaz de transformar visões do Eu com relação ao Outro e à sua própria cultura no "momento etnológico" todoroviano e salienta que o diálogo cultural permite a desestabilização de tendências polarizantes que 
em contraste com a escolha positivista de leis e generalizações empiricamente corroboradas como unidade fundamental de estudo científico. Além disso, com foco nas premissas e nas suposições, o sentido e o entendimento não são vistos como intrínsecos ao mundo, mas são continuamente construídos, defendidos e desafiados. O principal propósito é problematizar respostas, causar estranhamento no que se tornou familiar e reverter o processo de construção a fim de revelar o quão problemáticas são as estruturas do mundo políticosocial tidas como dadas. Em nível metodológico, tais transformações trazem uma clara orientação para o pluralismo, desafiando o monismo metodológico que busca institucionalizar critérios estandardizados, explícitos e imutáveis e criando uma imagem polimórfica de produção do conhecimento.

2 David BLANEY e Naeem INAYATULLAH, 2004, p. 7-17.

${ }^{3} \mathrm{G}$. John IKENBERRY, 2000.

${ }_{4}$ Marysia ZALEWSKI e Cynthia ENLOE, 1995.

${ }^{5}$ Claudia Regina RIBEIRO e Vera Helena SIQUEIRA, 2007.

6 Jill STEANS, 1997. objetificam a diferença. Tal iniciativa proporciona respostas aos desafios da interação com a diversidade por meio da autorreflexão crítica e da aliança entre críticas sociais culturalmente diversas à desigualdade, indo na direção oposta tanto do "movimento duplo" de equação entre diferença e inferioridade e de assimilação requerida pela possibilidade de "humanidade comum" como do mecanismo de partição, que rompe a reciprocidade no relacionamento com o Outro. ${ }^{2}$

Porém, grande parte das abordagens pós-colonialistas em Relações Internacionais ainda trabalha marginalmente, não se propôs a examinar ou relega em segundo plano as questões relacionadas a gênero e ao estudo das masculinidades, particularmente o papel das masculinidades ocidentais nos processos de formação, de expansão e de consolidação da ordem internacional, entendida aqui como uma série de arranjos estabelecidos entre atores no nível internacional que definem suas relações com os outros e as expectativas mútuas sobre sua interação. ${ }^{3}$ Abordagens feministas na teoria de Relações Internacionais como a de Zalewski e Enloe ${ }^{4}$ permitem observar como o discurso sobre segurança nesse processo de expansão é intensamente permeado por questões de gênero e de consolidação da masculinidade hegemônica, conceito que remete à definição de uma resposta correntemente aceita ao problema da legitimidade do patriarcado, que sustenta a posição dominante dos homens e a subordinação das mulheres. ${ }^{5}$ Nesse processo, aquilo que é associado à feminilidade, como as emoções individuais, é desvalorizado nas formas de pensamento dominantes; assim, o gênero age como um meio de contenção de certas formas de pensamento, de ação e de discurso, mostrando que as construções das identidades estratégicas têm o poder de inibir o que pode ser dito e pensado. Steans ${ }^{6}$ traz à tona a relação entre masculinidade, autoridade e violência tecnológica, que reafirma a inferioridade da experiência feminina, destrói a tradição de não violência e reforça a ligação entre militarismo e outras formas de dominação, como o sexismo. Tais formas estabelecem separações entre grupos e veem que a diferença deve ser subjugada ou eliminada. Porém, o pós-colonialismo pode permitir transcender tais reflexões, incorporando possibilidades mais robustas de transformação e mudança.

Visando a explorar tal possibilidade, o objetivo deste ensaio é discutir, com base numa perspectiva póscolonialista, o papel das masculinidades ocidentais em dois momentos de expansão da ordem internacional: as expansões colonial e imperialista dos séculos XVI a XIX e a construção da uma ordem internacional globalizada nos 
7 BLANEY e INAYATULLAH, 2004, p. 7-17; e Phillip DARBY, 1998, p. 919.

${ }^{8}$ A expressão "experiências de sofrimento", originalmente utilizada por BLANEY e INAYATULLAH, 2004, foi evitada para que se restrinja a possibilidade de que essa argumentação recaia num discurso vitimista sobre homens e masculinidades ou mesmo no risco de despolitização da questão. Nesta pesquisa, o foco se dá na crítica às relações binárias de poder que produzem a diferença como alteridade nas esferas da política, das instituições e das organizações sociais (Benedito MEDRADO e Jorge LYRA, 2008, p. 809-810). séculos XX e XXI. Mesmo que a definição e o conteúdo das masculinidades ocidentais variem de acordo com as diferenças de tempo e locais identitários, elas estabeleceram hierarquias no nível internacional entre um centro interpretativo soberano masculino/patriarcal - entendido como uma "realidade maior" ou uma "presença não problematizada" - e a diferença - compreendida como negação da identidade soberana ou alteridade-e permitiu, numa interseção com outras formas de dominação e de marginalização da diferença, a fixação e a reprodução de referenciais de forma artificial e a criação de espaços políticos diferenciados no sistema internacional. Ao determinarem aquilo que podemos falar, pensar e ser $e$ permitirem a articulação historicamente específica das relações entre a universalidade e a particularidade, tais masculinidades ocidentais compuseram um aparato de exclusão que viabilizou a discriminação tanto nas fronteiras do sujeito e do Estado soberano moderno como na fronteira do sistema de Estados e da própria modernidade, reproduzindo a exclusão do "Outro" como negação do "Eu" e a marginalização de formas alternativas à moderna quanto à produção de subjetividade.

Ao aplicar uma perspectiva pós-colonialista, ${ }^{7}$ defendo que é possível redefinir as Relações Internacionais como campo de conhecimento heterológico, com base no aprendizado do tratamento das ambiguidades geradas na interação com a diferença em relação ao gênero, no reconhecimento da diversidade e na exploração das possibilidades alternativas das "zonas de contato" psicológico e social, particularmente o diálogo potencial que colabora para a elucidação mútua de culturas e das relações de gênero. O reconhecimento do Outro dentro do Eu e o compartilhamento de experiências e de críticas à opressão e à exclusão ${ }^{8}$ visando à sua superação no pensamento e na prática não apenas funcionam como fontes de autorreflexão e transformação cultural, mas estabelecem a conversação entre tradições que respondem à marginalização gerada no processo de reprodução das masculinidades ocidentais. São recuperadas vozes recessivas na interpretação do contexto histórico e dos debates intelectuais - desessencializando entendimentos dominantes - e é estabelecido o vínculo entre tradições recessivas na própria identidade e as demais culturas a fim de se oferecer uma visão de libertação em relação à opressão para Eu e Outro. Nesse processo, os particularismos da experiência masculina ocidental com a diferença tratada em contraposição à identidade masculina nas perspectivas mais tradicionais da área - e do processo histórico de delimitação espaço-temporal de fronteiras 
${ }^{9}$ A Paz de Vestfália de 1648 referese a um conjunto de tratados que encerrou a Guerra dos Trinta Anos, iniciada com a intensificação da rivalidade política entre o Imperador Habsburgo do Sacro Império Romano-Germânico e as cidades-Estado luteranas e calvinistas no território do norte da atual Alemanha que se opunham ao seu controle. Tal guerra teve o envolvimento de potências católicas administradas pelos Habsburgo, como a Espanha e a Áustria, e também de Estados protestantes escandinavos e da França, que, mesmo sendo católica, temia o domínio dos Habsburgo na Europa e apoiou os protestantes no conflito. Enquanto o tratado entre a Espanha e os Países Baixos - a Paz de Münster, assinada no mês de janeiro - pôs fim à Guerra dos Oitenta Anos, os tratados assinados em Münster e em Osnabrück, em outubro, pelo Sacro Imperador Romano-Germânico Fernando III, pelos príncipes do Sacro Império Romano-Germânico, pela França e pela Suécia encerraram a luta dessas duas últimas potências com o Sacro Império. Nos estudos mais tradicionais sobre tal evento no estudo da história das relações internacionais, concebe-se que a Paz de Vestfália, além de consolidar a independência dos Países Baixos, abalou o poder do Sacro Imperador, além de ter autorizado que os governantes dos estados germânicos gozassem a prerrogativa de estipular a religião oficial dos territórios sem interferência externa e oferecido reconhecimento legal aos calvinistas (Adam WATSON, 1992, p. 182-197). A Paz de Vestfália é concebida como um marco fundamental do sistema laico das interações e dos princípios estatais modernos, como a soberania territorial, a não interferência na política doméstica dos demais Estados e a tolerância entre unidades políticas dotadas de direitos iguais. Como destaca Daniel PHILPOT, 1999, p. 567-569, Vestfália permitiu a constituição da sociedade rígidas também baseadas em questões de gênero são desvelados a fim de se transcender sua hegemonia e se recuperarem valores dominantes e recessivos do próprio Ocidente na dinâmica de sua reimaginação. Examinarei a seguir os momentos em foco nesta pesquisa.

\section{A masculinidade ocidental nas expansões colonial e imperialista dos séculos XVI a XIX}

A produção intelectual dos séculos XVI e XVII e as práticas políticas resultantes desse pensamento no nível internacional apontavam para um processo de preservação e de cristalização da integridade do "império da uniformidade" doméstico nos principais Estados nacionais modernos em formação na Europa naquele contexto. Após a Paz de Vestfália, ${ }^{9}$ o impulso dominante era a localização da diversidade como uma ameaça, de forma que a diferença era mantida no exterior pela defesa das fronteiras e contida na "cruzada interna" pela unidade da comunidade política doméstica. As implicações práticas e intelectuais da homogeneização cultural sistemática e da constituição uniformizadora das novas unidades políticas na Europa apontavam não só para a realocação do "problema da diferença" para a dimensão doméstica onde se esperava que a diversidade fosse administrada -e a perpetuação da violência com relação às minorias não conformadas à "fé nacional" dentro dessas unidades. A resposta hierarquizante e disciplinadora à diferença domesticamente transbordava para seu tratamento na esfera externa: entendida como elemento desestabilizador da harmonia doméstica, a diferença interna era gerenciada com hierarquia, erradicação, assimilação ou expulsão, enquanto a externa era vista como ameaça constante interditada nas fronteiras, enfrentada militarmente ou colonizada. ${ }^{10}$

Em face das guerras religiosas na Europa e dos desafios na incorporação dos ameríndios às visões de mundo europeias, o legado intelectual naturalizava a diferença como elemento desestabilizador da associação política unificada e harmoniosa. Pensadores modernos inseridos em empreendimentos de pacificação buscavam fundações não questionáveis da autoridade soberana e desproviam o "estado de natureza" da riqueza da sociedade civil. Grotius, por exemplo, buscava bases não problematizadas para uma ordem civil capaz de implementar a justiça natural e, embora refutasse um direito generalizado de violenta perseguição religiosa, não defendia proteção a dissidentes religiosos em face das 
internacional, com normas mutuamente acordadas que definem os detentores de autoridade e suas prerrogativas, sendo o Estado moderno essa autoridade detentora de soberania. O sistema de Estados soberanos exigia instituições estatais dentro das fronteiras e o desaparecimento de autoridades que interferissem de fora, para que a autoridade suprema vigorasse dentro do território e tivesse independência política e integridade territorial. Tal autoridade conota legitimidade - aqui entendida como o direito de controlar instituições e poderes e territorialidade, num momento em que as pessoas governadas pelos detentores de soberania são definidas pela locação dentro das fronteiras, não por relações familiares ou por crença religiosa. ${ }^{10}$ BLANEY e INAYATULLAH, 2004, p. 93-125.

11 BLANEY e INAYATULLAH, 2004, p. 35-43.

12 DARBY, 1998. necessidades políticas e oferecia justificativas para a violência no subjugo de não europeus no processo de colonização. Para Hobbes, a espacialização do poder no Estado soluciona o "perigo" da incerteza advinda da diversidade moral e religiosa. Na base da preservação do "bem público" como princípio regulador, Locke sugere que soberanos apliquem punições aos "incapazes" de seguir um padrão de sociedade baseado na propriedade e no comércio e defende pragmaticamente uma visão circunstancial de tolerância pela impossibilidade de se constituir uniformidade em questões religiosas de forma coercitiva e a conformidade cultural fortalecida pela sanção político-social, além de vislumbrar um mundo partido em Estados territoriais "civilizados", a usurpação das terras indígenas e a assimilação dos ameríndios aos padrões da sociedade civil europeia. A classificação dos ameríndios num estágio pré-social associado à desordem - o "estado de natureza" - procurava resguardar a precária noção de "superioridade cultural" europeia e fortalecer a justificativa de práticas coloniais. "1

Naquele contexto, a masculinidade do colonizador - associada à bravura na conquista de terras fora do continente europeu e à força na imposição de sistemas político-sociais europeus aos nativos na América naquele contexto - pressupunha a negação do feminino interior, a marginalização do discurso do Outro - em particular referente ao ameríndio - e a cristalização de uma concepção autorreferencial do exercício do poder e era, ao mesmo tempo, peça fundamental na construção de um empreendimento baseado no desenvolvimento de estratégias de dominação político-cultural da população local. ${ }^{12} \mathrm{~A}$ masculinidade do europeu alimentava a violência na atividade colonizadora e oferecia sustentação à ideia de superioridade militar do colonizador, que concebia os nativos como fracos e incapazes. O desenvolvimento de um aparato de produção econômica voltado para atender às necessidades metropolitanas - concebida pelo colonizador como mais dinâmica e forte que a local - conduzira à gradativa desorganização da produção ameríndia, enquanto o controle da sexualidade das mulheres pelo Estado e pela Igreja construía um tecido social colonial que criava condições de possibilidade para o fortalecimento do domínio masculino sobre a sociedade, particularmente no que dizia respeito ao direcionamento moral e religioso nas relações entre homens e mulheres e à associação dessas normas sociais com as assimetrias sociopolíticas em múltiplas áreas entre os colonizadores e os ameríndios. Naquela organização social, tais nativos eram submetidos a trabalhos forçados, enquanto as mulheres indígenas 
${ }^{13}$ Verena STOLCKE, 2006.

${ }^{14}$ STOLCKE, 2006.

${ }^{15}$ Beate JAHN, 2000. exerciam diversos serviços pessoais - inclusive sexuais - aos colonizadores. ${ }^{13}$

O empreendimento que resulta da interseção da masculinidade dominante do colonizador europeu com as ideias de superioridade racial e as assimetrias de classe social conduziu, como lembra Stolcke, ${ }^{14}$ a novos sistemas de identificação e hierarquização social no mundo colonial. $J^{J}{ }^{15}$ indica as dificuldades de classificação dos povos ameríndios recém-descobertos na composição cultural do entendimento cristão do mundo, tendo em vista que os ameríndios não poderiam ser vistos como "anticristãos" por não terem sequer conhecimento prévio da Cristandade. Tornavam-se, assim, irrelevantes categorias legais disponíveis na estrutura cultural dos hispânicos, por exemplo, para "guerras justas" ou escravidão para sua classificação. Num projeto totalizante de sistemática assimilação cultural dos ameríndios em novas categorias desenvolvidas pelos hispânicos, os ameríndios eram concebidos como dotados de potencial de razão, mas sem qualquer cultura ou com uma "falsa cultura" que tangenciava a lei natural; eram, assim, receptáculos potenciais dos elementos culturais hispânicos, sendo a masculinidade do colonizador um dos fatores que reforçavam a imposição desses elementos. O efeito foi uma hierarquia sustentada numa interpretação linear da história - que acomodava o ameríndio no "estado de natureza", num tempo distinto dos europeus -, intimamente ligada à prática políica que reproduzia a força e a superioridade militar do colonizador e conduzia à crescente desorganização da produção local. Ampliando o escopo desse argumento, a concepção universal de "estado de natureza" criou condições para ordenação de culturas em "estágios de desenvolvimento", oferecendo sustentação para abordagens sobre relações desiguais entre comunidades políticas.

As abordagens pós-colonialistas permitem, ao considerar a masculinidade europeia e a questão do gênero envolvida nesses sistemas de identificação, vislumbrar uma ambiguidade na caracterização da diferença. Se por um lado a diferença ameríndia era vista como fonte de desordem que deveria ser eliminada, dominada ou excluída, por outro ela poderia ser vista como desejo. Isso sugeria a possibilidade de entendimentos ético-políticos alternativos na "zona de contato" com tal diferença, de forma que a suposta "selvageria" presente no ameríndio era uma possibilidade em cada ser humano e, além de perigo, representava desejo. Têm-se, assim, elementos que explicitam possibilidades de engajamento com a diferença, permitindo reconhecer elementos de contato. O papel da diferença é, assim, reconsiderado a partir da exploração 
${ }^{16}$ BLANEY e INAYATULLAH, 2004, p. 58-85; e DARBY, 1998.

${ }^{17}$ Edward KEENE, 2002, p. 112.

${ }^{18}$ KEENE, 2002, p. 5-6. do contraimpulso de regeneração e apreciação da diversidade como meio de autorreflexão, evidenciando-se a possibilidade de respostas alternativas na forma de "momentos etnológicos". Nesse sentido, a ambiguidade na caracterização da diferença como "selvageria" - concebida tanto como fonte de desordem como de desejo - não apenas desvela a tentativa de autopreservação europeia em face da alteridade, mas sugere a possibilidade de entendimentos ético-políticos alternativos: o pensamento que reitera "momentos dominantes" também traz elementos recessivos que explicitam possibilidades de engajamento com a diferença, permitindo reconhecer o "índio interno" e fortalecer elementos de redenção. No legado intelectual, isso pode ser visto no uso do indígena por Grotius para a criação de um "espaço de dúvidas" em relação à diferença a fim de indicar que um tratamento mais respeitoso ao Outro externo poderia originar ações semelhantemente tolerantes com relação aos Outros internos na própria Europa. No que diz respeito à masculinidade europeia, o desejo que a mulher ameríndia provocava no colonizador europeu evidencia a possibilidade de uma cultura simbiótica entre colonizador e colonizado. A insegurança e a dúvida do colonizador diante do temor em relação ao potencial desestabilizador do desejo por essa diferença operam fora das regras de engajamento estipuladas pelo dominador e se configuram, no mínimo, como limites ao exercício indiscriminado de seu poder. A concepção ameaçadora da mulher ameríndia - que provoca o medo e o desejo - e a feminização do próprio continente americano captam a dificuldade no tratamento da diferença e representam desafios à estrutura de poder colonial e subversões à noção masculinizada europeia dominante de política. ${ }^{16}$

No século XIX, o conceito de "civilização" - entendido por John Stuart Mill como desenvolvimento material em termos de progresso econômico e tecnológico e moral na forma de "bons governos" baseados em sistemas políticos e jurídicos justos e eficientes ${ }^{17}$ - alicerçou a conquista imperialista de povos considerados "atrasados" e, a partir da hierarquização e da discriminação do não europeu, viabilizou a resolução da contradição entre duas estruturas legais e institucionais no nível internacional: uma ordem "europeia" voluntarista e descentralizada, assinalada pela tolerância à diferença político-cultural e pelo respeito à autoridade de Estados independentes e juridicamente semelhantes; e outra "extra-europeia" mais centralizada, na qual operavam a divisão de soberania, o reforço dos direitos individuais sobre propriedade e a propagação de modelos particulares de sociedade dos poderes imperialistas a sistemas políticosociais locais. ${ }^{18}$ Naquele contexto, o objetivo da expansão 
19 James JOLL, 1976.

${ }^{20}$ R. B. J. WALKER, 2005, p. 2. imperialista - inserida num contexto de uma nova fase do capitalismo marcada pela fusão do capital bancário e do capital industrial - era o reinvestimento do capital acumulado, já que o espaço nos limites do Estado-nação não era suficiente para a reprodução do capital, bem como a busca de novos mercados consumidores, a necessidade de controlar regiões produtoras de matérias-primas essenciais à indústria, a necessidade de dirigir excedentes populacionais para outras áreas não europeias, a conquista de pontos estratégicos para a defesa de colônias já existente e a missão "civilizadora" de povos considerados "atrasados". ${ }^{19}$

A estigmatização do não europeu como "selvagem" ou "bárbaro" que deveria ser convertido ao padrão civilizacional europeu solucionou o dilema de interação com a diferença ao traduzi-la como inferioridade: ${ }^{20}$ a diversidade era objetificada e disciplinada, visando-se a preservar a coesão da identidade dos Estados europeus conquistadores. Naquele contexto, a masculinidade europeia vinha associada de forma ainda mais complexa ao discurso de superioridade racial, que justificava a missão civilizatória: a própria produção de conhecimento nesse momento aponta para um raciocínio utilitarista que transforma o saber sobre o outro em conhecimento para dominação. O empreendimento geopolítico resultante dividiu África, Ásia e Oceania em zonas de neocolonização europeia, implicando o uso instrumental da violência a serviço de interesses econômicos das burguesias das metrópoles. Porém, ao apontar que os encontros coloniais à época da expansão imperialista no século XIX também envolvem ambivalência do colonizador e do colonizado e que podem existir momentos de cumplicidade com a diferença localizada dentro e fora, a ênfase trazida por póscolonialistas como Darby ${ }^{21}$ na orientação pessoal e cultural viabiliza a contínua expansão do entendimento do político, já que transforma elementos como as obras de arte, por exemplo, em repositórios desse entendimento, tendo em vista que a política adquire seu sentido a partir da cultura. Numa perspectiva inclusiva entre as múltiplas facetas da vida humana, essa ênfase contextualiza à vida cotidiana a política, em vez de concebê-la como uma esfera autônoma de ação e pensamento. As experiências dos indivíduos são contadas ao longo das do seu grupo, e, como os sistemas de troca são mediados pela experiência vivida, o mundo exterior - como a dimensão do Estado e a interação diplomática - é concebido em relação ao interior sociocultural, pessoal e subjetivo, que abarca formas de comportamento e emoções. A personalização das questões direciona a atenção para condições mutáveis que 


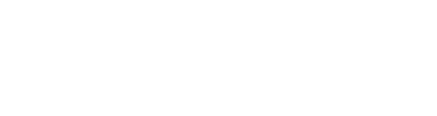

estabelecem os padrões de interação social, tendo a capacidade de promover a reavaliação de sensibilidades e valores.

Reconceituando-se o imperialismo, as narrativas ficcionais sobre a conquista imperialista evidenciam a vulnerabilidade e a transitoriedade da supremacia ocidental - inclusive no que dizia respeito às questões de gênero - e salientam contramovimentos que introduzem perspectivas de mudança e intercursos entre o moderno e o tradicional que não estão encapsulados em antagonismos recíprocos. Desvela-se, assim, que as linhas divisórias que conduziam à dominação sustentada pela masculinidade europeia e ao absolutismo moral na rejeição de outros povos são traçadas parcialmente pela insegurança e pelo desejo em relação ao Outro pelos seus elementos de diferença e sua similaridade com tempos passados. Explicita-se que categorias cristalizadoras aplicadas na análise do encontro entre Ocidente e África/Ásia marginalizam ansiedades e desejos compartilhados característicos do intercâmbio cultural. A força do argumento pós-colonialista é, assim, a sensibilidade moral que pode estimular a reconfiguração do pensamento, particularmente com a orientação para a dimensão pessoal e a direção do foco para a subjetividade da experiência vivida por indivíduos situados em contextos de intercâmbio cultural e de negociação com a diferença. A releitura da masculinidade dominante que orientou a conquista imperialista a partir desse procedimento comprova que, indo-se além da consideração de seus atributos materiais e manifestações externas, o sentido da primazia imperial não pode ser desvinculado do pensamento daqueles que a exercem - particularmente de seus excessos e inibições - e dos que a experimentam. A insegurança, a dúvida e o temor em relação à diferença que opera fora das regras de engajamento estipuladas pelo dominador são trazidos à tona, por exemplo, pela ficção e se configuram como limites ao exercício efetivo de poder. As inclinações masculinas dos textos acerca da intervenção europeia na Ásia e na África são permeadas por homoerotismo e a concepção ameaçadora da mulher, os quais captam a dificuldade no tratamento da diferença e representam desafios à estrutura de poder imperial e subversões às noções masculinizadas de política, explicitando sua vulnerabilidade. Na personalização da relação indo-

${ }^{22}$ Como exemplos, cabe citar a obra de E.M.Forster A Passage to India e a de Dennis Kincaid Their Ways Divide. Para uma análise aprofundada da literatura indobritânica sobre tal período, ver DARBY, 1998. britânica na ficção, ${ }^{22}$ por exemplo, a relevância do argumento proposto está na elucidação dos traços de cultura compartilhada entre as partes, que expõem a ambivalência da relação imperial - inclusive nas relações de amizade, cumplicidade e atração homoerótica entre colonizador e colonizado -, e do papel alegórico das 
${ }^{23}$ KEENE, 2002, p. 9-10.

${ }^{24}$ KEENE, 2002, p. 137-139.

${ }^{25}$ David HELD e Anthony McGREW, 2000. categorias derivadas do comportamento interpessoal para a sondagem do políico, de forma a comprovar que o pessoal é político ou representa uma extensão dele.

\section{As masculinidades ocidentais na construção de uma ordem internacional globalizada nos séculos XX e XXI}

O compartimento rígido entre uma ordem intraeuropeia promotora de "tolerância" e uma extraeuropeia na qual se impunham modelos de "civilização" foi dissipado no século $X X$, com a gradual interpenetração dos dois modelos de ordem no alargamento da "sociedade de Estados" e na constituição de uma "ordem globalizada" por um procedimento em mão dupla: o reconhecimento da soberania e da tolerância político-cultural com relação a povos não europeus e a difusão da "civilização" na própria Europa após a barbárie promovida por europeus naquele mesmo século com a Segunda Guerra Mundial. No entanto, tal reconhecimento permanecia condicionado à assimilação de standards "civilizacionais" ocidentais, a partir de então abalizados no repúdio gradual à violência de uma supremacia patriarcal que servira como um dos mecanismos de legitimação da ordem bifurcada no passado. ${ }^{23}$ Com o questionamento da "autoconfiança" europeia na disseminação de seu modelo de sociedade ao restante do mundo após a "selvageria" das guerras mundiais em seu território e o colapso da estratificação austera entre ambas as ordens, o conceito de "civilização" preservou elementos centrais de progresso e "bom governo" e plasticamente abandonou a dimensão explícita de uma concepção discriminatória por gênero e raça, mas permanecendo como objetivo a ser atingido por toda a humanidade. ${ }^{24}$

A globalização pode ser vista como um conjunto de processos que modificaram a forma espacial de organização humana para padrões transcontinentais e inter-regionais de atividade, de interação e de exercício de poder. Tal conjunto não é uma condição singular ou um processo linear; em vez disso, deve ser concebido como um fenômeno multidimensional que envolve domínios de atividades e de interação que incluem a esfera econômica, a política, a tecnológica, a militar, a legal, a cultural e a ambiental, com diferentes modelos de relacionamento: ${ }^{25}$

[...] a globalização denota a escala crescente, a magnitude progressiva, a aceleração e o aprofundamento do impacto dos fluxos e dos padrões inter-regionais de interação social. Refere-se a uma mudança ou transformação na escala de organização 
${ }^{26}$ HELD e MCGREW, 2000, p. 13.

${ }^{27}$ HELD E MCGREW, 2000.

${ }^{28}$ Raewyn CONNELL, 1995.

${ }^{29}$ RIBEIRO E SIQUEIRA, 2007.

${ }^{30}$ Michael KIMMEL, 1997. social que liga comunidades distantes e amplia 0 alcance das relações de poder nas grandes regiões e continentes do mundo. ${ }^{26}$

É possível distinguir diferentes formas históricas da globalização por meio da avaliação da extensão das redes de relações e conexões, da intensidade dos fluxos e dos níveis de atividade dentro dessas redes e do impacto desses fenômenos em comunidades particulares. Sob tal ótica, diversos regimes de ordem pessoal e de controle direto, com seus problemas e incertezas, cederam espaço na contemporaneidade a novas formas transnacionais de organização e de atividade, marcadas mais frequentemente por sistemas anônimos de poder, que começaram a se desenvolver independentemente dos Estados-nação nos quais se iniciaram. Em vez de impérios territoriais que submetem inúmeras regiões a um único sistema político, uma nova ordem política começou a se desenvolver, baseada na proliferação de organizações internacionais, práticas transnacionais e redes de troca na indústria e na atividade bancária, nos setores de informação e de comunicação e no intercâmbio cultural. Teve-se uma ordem global fundamentalmente interconectada, marcada por densos modelos de troca, mas também pelo poder, pela hierarquia e pela desigualdade. ${ }^{27}$

Na expansão da globalização, a mídia foi um ator fundamental no processo de difusão de novos papéis sociais, inclusive os relacionados às masculinidades. Em tal contexto, observa-se uma desestabilização crescente da ideia de masculinidade hegemônica no Ocidente. Com a redefinição da masculinidade ocidental, as perspectivas da masculinidade hegemônica organizadas em torno do heroísmo da violência foram perdendo espaço após a Segunda Guerra Mundial, de forma a serem substituídas por noções ligadas à racionalidade tecnocrática, à meritocracia burguesa, à competitividade e à confiança num mundo corporativo, inseridas na expansão do liberalismo após a década de 1970. Além disso, a feminização da força de trabalho - que, em diversos Estados, minou a autoridade masculina na família e reduziu o valor de atributos masculinos hegemônicos no mercado ${ }^{28}$ - e o fortalecimento dos movimentos feminista e LGBT também estimularam transformações na representação da masculinidade hegemônica.

Como ressaltam Ribeiro e Siqueira, ${ }^{29}$ novas representações na forma de masculinidades subalternas ocidentais - "indivíduos do sexo masculino que se mostram pouco vinculados às práticas e discursos considerados próprios aos homens de uma dada sociedade" - vêm sendo disseminadas no processo de globalização. Kimmel ${ }^{30}$ lembra 
${ }^{31}$ WALKER, 2005, p. 1. que os significados da masculinidade não são fixos ou dados e assumem caráter contextual, podendo variar de acordo com a cultura e ao longo do tempo para cada ser humano. Ao trazermos a discussão em foco para as Relações Internacionais, as múltiplas transformações do conceito de masculinidade - bem como outros conceitos ligados ao aparato de exclusão e de marginalização da diferença no nível internacional - não necessariamente supuseram sua superação como ideal regulador moderno, mesmo num contexto de reconfiguração dos contornos globais. Walker ${ }^{31}$ ressalta que, apesar da desestabilização gradativa de inúmeras segmentações no processo de globalização, as fronteiras artificiais, mesmo que não permaneçam onde estavam, ainda demarcam antagonismos. No caso, mesmo a difusão de uma concepção mais flexível de masculinidade a partir de referenciais ocidentais continuaria reproduzindo a exclusão e a marginalização de outros entendimentos cultural e temporalmente distintos do conceito, consolidando hierarquias mesmo que proponha maior abertura a concepções alternativas à masculinidade hegemônica ocidental.

Ainda assim, a emergência e a difusão de masculinidades ocidentais subalternas poderiam, numa lógica pós-colonialista, sinalizar para um tratamento das ambiguidades geradas na interação com a diferença, reconhecendo a possibilidade da diversidade com relação aos processos de construção da masculinidade e a exploração das possibilidades alternativas das "zonas de contato" psicológico e social. Dentre elas, a característica mais flexível e aberta das masculinidades ocidentais subalternas, mesmo que ainda reproduza uma lógica culturalmente específica que promova a exclusão de outros entendimentos do conceito de masculinidade - como os não ocidentais -, pode viabilizar o início de um diálogo potencial para a elucidação mútua de culturas e das relações de gênero. $O$ reconhecimento dessa diversidade e o compartilhamento de experiências e de críticas à exclusão promovida por tais relações de poder orientadas pelas masculinidades ocidentais dominantes no passado e no presente podem permitir a autorreflexão e a conversação entre tradições que buscam responder à opressão no processo de constituição das masculinidades. São recuperadas vozes recessivas na interpretação do contexto histórico, o que permite aos ocidentais a reimaginação de suas próprias comunidades políticas a partir do repensar do papel das masculinidades e das questões de gênero na construção do tecido social. 


\section{Considerações finais}

Este ensaio traz apenas reflexões iniciais voltadas para a maior consideração dos temas relacionados a gênero na área de Relações Internacionais a partir de uma perspectiva pós-colonialista. Tal perspectiva permite a incorporação de possibilidades mais robustas de transformação dos papéis da masculinidade ocidental no processo de expansão da ordem internacional. Ainda que os conceitos que definem tal masculinidade variem com base nas diferenças de cultura, tempo e locais identitários, elas estabeleceram hierarquias entre identidade e diferença. Mesmo assim, é possível pensar no reconhecimento da diversidade e na exploração das possibilidades alternativas das "zonas de contato" psicológico e social, compartilhando experiências e críticas à marginalização promovida no âmbito de práticas binárias de poder com o objetivo de superá-las no pensamento e na prática. Pode-se, assim, viabilizar a conversação entre tradições que respondem à opressão gerada no processo de reprodução das masculinidades ocidentais.

\section{Referências bibliográficas}

BLANEY, David L., and INAYATULLAH, Naeem. International Relations and the Problem of Difference. New York: Routledge, 2004.

CONNELL, Raewyn W. Masculinities. Cambridge: Polity Press, 1995.

DARBY, Phillip. The Fiction of Imperialism: Reading between International Relations and Postcolonialism. London and Washington, D.C.: Cassell, 1998.

HELD, David, and MCGREW, Anthony. Prós e contras da globalização. Rio de Janeiro: Jorge Zahar Editor, 2000.

IKENBERRY, G. John. "Varieties of Order: Balance of Power, Hegemonic, and Constitutional." In: After Victory: Institutions, Strategic Restraint, and the Rebuilding of Order after Major Wars. Princeton: Princeton University Press, 2000. p. 21-49.

JAHN, Beate. The Cultural Construction of International Relations: The Invention of the State of Nature. Houndmills, Basingstoke, Hampshire and New York: Palgrave, 2000.

JOLL, James. "Imperialism." In: . Europe since 1870: An International History. 2nd. Harmondsworth, Midd.: Penguin Books, 1976. p. 78-112.

KEENE, Edward. Beyond the Anarchical Society: Grotius, Colonialism and Order in World Politics. Cambridge, UK, and New York: Cambridge University Press, 2002. 
KIMMEL, Michael S. "Homofobia, temor, vergüenza y silencio en la identidad masculina". In: VALDÉS, Teresa; OLIVARIA, José (Eds.). Masculinidade/s: poder y crisis. Santiago, Chile: Isis Ediciones de las Mujeres/FRACSO, 1997. p. 49-62.

LAPID, Yosef. "The Third Debate: On Prospects of International Theory in a Post-Positivist Era." International Studies Quarterly, v. 33, n. 3, 1989. p. 236-254.

MEDRADO, Benedito; LYRA, Jorge. "Por uma matriz feminista de gênero para os estudos sobre homens e masculinidades". Revista Estudos Feministas, v. 16, n. 3, p. 809-840, 2008.

PHILPOTT, Daniel. "Westphalia, Authority, and International Society." Political Studies, v. XLVII, n. 3, 1999. p. 566-589. RIBEIRO, Claudia Regina; SIQUEIRA, Vera Helena Ferraz. "O novo homem na mídia: ressignificações por homens docentes". Revista Estudos Feministas, v. 15, n. 1, 2007. Disponível em: http://www.scielo.br/scielo.php?script=sci arttext\&pid=S0104-026X2007000100013\&lng=en\&nrm=iso. Acesso em: 18 dez. 2009.

STEANS, Jill. Gender and International Relations: An Introduction. Cambridge: Polity Press, 1997.

STOLCKE, Verena. "O enigma das interseções: classe, 'raça', sexo, sexualidade: a formação dos impérios transatlânticos do século XVI ao XIX". Revista Estudos Feministas, v. 14, n. 1, p. 15-42, 2006. Disponível em: $\mathrm{h} \dagger \mathrm{t} \mathrm{p}:$ / / w w w. s c i e l o. b r / scielo.php?script=sci_arttext\&pid=s0104026X2006000100003\&lng =en\&nrm =iso. Acesso em: 18 dez. 2009.

WALKER, R.B.J. "The Doubled Outsides of the Modern International." 5th International Conference on Diversity in Organizations, Communities and Nations. Beijing, 2005.

WATSON, Adam. The Evolution of International Society: A Comparative Historical Analysis. London and New York: Routledge, 1992.

ZALEWSKI, Marysia, and ENLOE, Cynthia. "Questions about Identity in International Relations." In: BOOTH, Ken, and SMITH, Steve (eds.). International Relations Theory Today. University Park: The Pennsylvania University Press, 1995. p. 279-305.

[Recebido em dezembro de 2009 e aceito para publicação em agosto de 2010]

\section{Brave New Worlds: A Post-Colonialist Perspective on Western Masculinities}

Abstract: The purpose of this essay is to discuss, based on a post-colonialist perspective, the role of Western masculinities in two moments of the expansion of the international order: the colonial and imperialist expansion from the sixteenth to the nineteenth century and the construction 
of a global international order in the twentieth and twenty first centuries. Although the concepts that define such masculinities vary based on differences of culture, time and local identities, they established hierarchies between identity and difference. Still, it is possible to think about the recognition of diversity and the exploration of alternative possibilities of psychological and social "contact zones". That would occur with the sharing of experiences and of criticism as to the production of otherness consolidated by binary relations of power in social and political institutions, aiming to overcome those exclusionary practices in thought and in behavior. This sharing allows for a conversation among traditions that respond to the oppression generated in the process of the reproduction of Western masculinities.

Key Words: International Relations; Masculinities; Post-Colonialism. 